\title{
Anthropometric Characteristics of Polycystic Ovary Syndrome and Their Associations with Insulin Resistance and Lipid Profile
}

\author{
María L. Sánchez-Ferrer 1,2,+ ${ }^{D}$, Julián J. Arense-Gonzalo ${ }^{2,3,+} \mathbb{D}$, María T. Prieto-Sánchez ${ }^{1,2, *(\mathbb{D})}$, \\ Inmaculada Gómez-Carrascosa ${ }^{1} \mathbb{D}$, Ana I. Hernández-Peñalver ${ }^{1}$, Jaime Mendiola ${ }^{4} \mathbb{D}$ \\ and Alberto M. Torres-Cantero $2,3,4,5$ i
}

Citation: Sánchez-Ferrer, M.L.; Arense-Gonzalo, J.J.; Prieto-Sánchez, M.T.; Gómez-Carrascosa, I. Hernández-Peñalver, A.I.; Mendiola, J.; Torres-Cantero, A.M. Anthropometric Characteristics of Polycystic Ovary Syndrome and Their Associations with Insulin Resistance and Lipid Profile. Appl. Sci. 2021, 11, 5395. https://doi.org/ 10.3390/app11125395

Academic Editors: José Miguel Martínez-Sanz, Antonio Jesús Sanchez-Oliver,

Raquel Vaquero-Cristobal, Raul Domínguez Herrera and Arkady Voloshin

Received: 29 April 2021

Accepted: 8 June 2021

Published: 10 June 2021

Publisher's Note: MDPI stays neutral with regard to jurisdictional claims in published maps and institutional affiliations.

Copyright: (C) 2021 by the authors Licensee MDPI, Basel, Switzerland. This article is an open access article distributed under the terms and conditions of the Creative Commons Attribution (CC BY) license (https:// creativecommons.org/licenses/by/ $4.0 /)$.
1 Department of Obstetrics \& Gynecology, "Virgen de la Arrixaca” University Clinical Hospital, 30120 El Palmar (Murcia), Spain; marisasanchez@um.es (M.L.S.-F.); inmagc92@gmail.com (I.G.-C.); hernandezpenalver@gmail.com (A.I.H.-P.)

2 Institute for Biomedical Research of Murcia, IMIB-Arrixaca, 30120 El Palmar (Murcia), Spain; julianjesus.arense@um.es (J.J.A.-G.); amtorres@um.es (A.M.T.-C.)

3 Division of Preventive Medicine and Public Health, Department of Public Health Sciences, University of Murcia School of Medicine, 30100 Espinardo (Murcia), Spain

4 CIBER Epidemiología y Salud Pública (CIBERESP), Instituto de Salud Carlos III, 28029 Madrid, Spain; mendiola.j@gmail.com

5 Department of Preventive Medicine, "Virgen de la Arrixaca" University Clinical Hospital, 30120 El Palmar (Murcia), Spain

* Correspondence: mt.prieto@um.es; Tel.: +34-868888132

$+\quad$ The first two authors contributed equally to this manuscript and should be regarded as joint first authors.

\begin{abstract}
This study evaluates whether women with PCOS have a different body composition than non-PCOS women (controls), estimated by anthropometric methods, and whether body composition and PCOS condition could be predictors of insulin resistance (IR) and lipid profile (LP) in an independent manner. A case-control study was conducted in which women (126) were diagnosed with PCOS by the Rotterdam criteria and controls (159) were women without PCOS attending the gynecological clinic for routine examinations. Women with PCOS had higher body mass index, percentage of fat mass, and testosterone than controls. A higher fat mass predicted higher levels of triglycerides, LDL-c, and lower levels of HDL-c independently of PCOS condition. HOMA-IR was related to fat mass and was more significant in patients with PCOS. A higher bone mass was associated with lower total cholesterol and LDL-c independent of PCOS condition. Lower HOMA-IR remained associated with PCOS regardless of bone mass. Lean mass percentages predicted a better metabolic profile (lower triglycerides and higher HDL-c), and was also modulated by PCOS condition. Our results highlight the importance of body composition as an anthropometrical characteristic of PCOS, and the relationship of fat mass with a worse metabolic profile. In addition, PCOS condition was associated with worse HOMA-IR independent of body composition.
\end{abstract}

Keywords: polycystic ovary syndrome; anthropometry; body composition; metabolic profile

\section{Introduction}

Polycystic ovary syndrome (PCOS) is a reproductive and metabolic endocrine disorder [1] that causes anovulation and hyperandrogenism in women [2,3]. It affects from 4 to $21 \%$ of females depending on the source and diagnostic criteria [4]. PCOS is associated with lifelong morbidities with an increased risk for metabolic syndrome, type-2 diabetes mellitus, cardiovascular disease, endometrial carcinoma [5,6], and obesity [7-9], among others. There are many theories about its etiopathogenesis and on the role of the endocrine environment on these women. Women with PCOS have a lower concentration of sex hormone-binding globulin and higher androgen production from ovarian and suprarenal 
origins. There is also higher insulin secretion and insulin resistance [10]. The excess androgens play a major role in the development of central obesity typical of the masculinized pattern in PCOS [3,11-15]. Both the excessive weight and the central distribution of fat are related to an increased risk of anovulation and infertility in these women [16]. Body composition, rather than body weight, is related to obesity origins, as well as to metabolic and hormonal disorders $[17,18]$. However, it remains unclear what the best method to correlate body composition with metabolic parameters is (glycemic and lipid determinations). Several methods have been traditionally used to study body composition, such as anthropometry [19-21], impedanciometry, dual-energy X-ray absorptiometry (DEXA), magnetic resonance imaging (MRI), and computed tomography scan (CAT scan). The determination of body composition includes the proportion of different tissues in the body, especially adipose or fat mass, lean mass, and bone mass. This is important not only to quantify the excess of fat, but also for its relationship with other body components that may have a clinical impact. Anthropometry, according to the International Society of the Advancement of Kinanthropometry (ISAK), quantifies the three primary components of the body structure, describing them in agreement with the embryological layers from which they derive [19-22]. The skinfold caliper measurement, as an indirect anthropometric technique, is the most cost-effective method due to its validity and reliability at a minimal equipment cost and technical training, enabling the estimation of whole-body fat [23] Skinfold measurements have showed a high correlation with the percentage of body fat obtained with other techniques (densitometry, DEXA, and dilutional methods). For that reason, it is considered the gold standard among anthropometric measurements [24].

To the best of our knowledge, there are no studies exploring the differences in body composition between women with or without PCOS using anthropometric measurements according to the ISAK, nor investigating its relationship with laboratory abnormalities showing potential adverse metabolic disorders $[25,26]$. We hypothesize that patients with PCOS may have a different body composition than controls, and that these differences may also be correlated with different lipid profiles and insulin resistance. We wonder whether body composition and PCOS are independent, summative, or influencing risk factors related to alterations in lipid profile or insulin resistance.

\section{Materials and Methods}

\subsection{Study Population}

This was a case-control study conducted from September 2014 to May 2016 in the Department of Obstetrics and Gynecology of the University Clinical Hospital Virgen de la Arrixaca (HCUVA) in Murcia (Spain). The study design and method were previously described [27]. All participants were between 18 and 40 years old.

Cases $(n=126)$ were women attending the gynecology unit of the hospital, and included prevalent and incident (newly diagnosed) cases. Cases, whether incident or prevalent, were included only if a diagnosis could be established following the Rotterdam criteria [12], including medical history with a modified Ferriman-Galwey (mF-G) score [28], transvaginal ultrasound (TVUS), and reproductive hormone levels. Briefly, a diagnosis of PCOS required completion of at least two of the following three criteria: (i) hyperandrogenism, either biochemical (total testosterone level $\geq 2.6 \mathrm{nmol} / \mathrm{L}$ ) or clinical (mF-G score $\geq 12$ ) [29] and with or without acne or androgenic alopecia; (ii) oligoand/or anovulation (menstrual cycles $>35$ days or amenorrhea $>3$ months); and (iii) polycystic ovarian morphology (POM) on TVUS ( $\geq 12$ follicles measuring $2-9 \mathrm{~mm}$ in diameter, mean of both ovaries) [30]. Moreover, the following phenotypic subtypes of PCOS were also assessed (National Institutes of Health, 2012): hyperandrogenism + oligo/amenorrhea, hyperandrogenism + POM, oligo/amenorrhea + POM, and hyperandrogenism + oligo/amenorrhea + POM.

Controls $(n=159)$ were women without PCOS (or other major gynecological conditions, e.g., endometriosis) attending the gynecological outpatient clinic for routine gynecological examinations. The same procedures were performed with both cases and controls. 
Written informed consent was obtained from all subjects. This study was approved by the Ethics Research Committee of the HCUVA (no. 770/2013, approved 3 October 2013).

\subsection{Gynecological History and Hormonal Analysis}

Case subjects and controls were interviewed in person by two gynecologists. All participants underwent a physical and gynecological examination including TVUS and blood analyses during the early follicular phase between days 2 and 5 of the menstrual cycle at a scheduled clinical visit. Uterine and ovarian morphology were evaluated with TVUS (Voluson E8 ${ }^{\circledR}$ and 4-9 MHz transducer; General Electric Healthcare, Chicago, IL, USA). One fasting blood sample was drawn between 8 and 10 a.m. on the same day of the clinical appointment. Biochemical samples were performed in the Clinical Analysis Service at the HCUVA. Glucose, total cholesterol, TG, and HDL-c were measured using an automatic analyzer (Roche-Hitachi Modular PyD Autoanalyzer, Mannheim, Germany). LDL-c was calculated by Friedewald formula: LDL-c $\frac{1}{4}$ TC-(HDL-c + TG/5). Insulin was analyzed by chemiluminescence (DIAsource INS-IRMA; Belgium). Insulin resistance was calculated using the homeostasis model assessment index, as defined by the equation homeostasis model assessment $=$ fasting glucose $(\mathrm{mM}) \times$ fasting insulin $(\mu \mathrm{U} / \mathrm{mL}) / 22.5$ according to Matthews et al. [31]. Testosterone was determined using a time-resolved electrochemiluminescence immunoassay (Roche Diagnostic Corporation, Indianapolis, IN, USA).

\subsection{Physical and Anthropometric Measurements}

Weight and height were measured using a digital scale (Tanita SC 330-S, London, UK) and BMI was calculated. Anthropometric measurements were taken according to the restricted profile protocol of the international standards for the anthropometric evaluation of the International Association for the Advancement of Kineanthropometry (ISAK) (Figure S1). The recommended material was used according to ISAK: a Holtain-brand plicometer, a modified king foot as a caliper, an anthropometer of curved branches, a tape measure, digital scales (model Tanita SC 330-S, London, UK), curved branches or pelvis, a demographic pencil, alcohol, and gauze. The examiners were blinded to the condition of PCOS. Medidept software 2006 version 3.53 was used to calculate the percentages of bone and lean and fat mass in women with PCOS and controls by utilizing the formula by Jackson and Pollock (1980) [32].

\subsection{Statistical Analyses}

Descriptive statistics for continuous variables were summarized by mean, standard deviation (SD), median, and 5th-95th percentiles, and categorical variables are given as a percentage (\%) with a $95 \%$ confidence interval $(95 \%$ CI). Normality (KolmogorovSmirnov test) and equal variances were confirmed before bivariate analysis. Differences between women with PCOS and controls were evaluated by unpaired Student $T$-test or Mann-Whitney test where appropriate.

Unadjusted and adjusted multiple linear regression analysis was performed to examine associations between lipid profile (TG, HDL-c, LDL-c, total cholesterol), HOMA-IR, and body composition (lean, fat, and bone mass). The PCOS group was included in multivariable models along with age and testosterone to assess potential confounding as well as possible interactions between them. Interaction terms were considered but did not show significant influence and were excluded from the final models. The results of the linear regression models are reported as unstandardized coefficients $(\beta)$ and $95 \%$ CI. Finally, a linear regression model with interaction effects was performed to explore the potential influence of PCOS condition on the association between age and lipid profile.

All tests were two-tailed and the level of statistical significance was set at 0.05. Statistical analyses were performed with the statistical package IBM SPSS 23.0 (IBM Corporation, Armonk, NY, USA). 


\section{Results}

Table 1 shows anthropometric measurements and analytical determinations in PCOS and control subjects. Controls were older than cases ( 30.7 vs. 27.4 years old) and, as expected, cases had higher BMI than controls (25.2 vs. $\left.23.5 \mathrm{~kg} / \mathrm{m}^{2}\right)$. Regarding body composition, we found significantly higher fat mass percentages in women with PCOS compared to controls (30.0 vs. $27.6 \%$ ). No significant differences were found in the percentages of lean and bone mass between groups.

Table 1. Anthropometric measurements and analytical determinations in PCOS and control subjects.

\begin{tabular}{|c|c|c|c|c|c|}
\hline \multirow{2}{*}{ Characteristics } & \multicolumn{2}{|c|}{ Controls $(n=159)$} & \multicolumn{2}{|c|}{$\operatorname{PCOS}(n=126)$} & \multirow{2}{*}{$p$-Value } \\
\hline & Mean (SD) & Median (5-95) & Mean (SD) & Median (5-95) & \\
\hline Age (years) & $30.68(5.84)$ & $32.00(21.00-39.00)$ & $27.38(5.08)$ & $28.00(19.00-35.65)$ & 0.000 \\
\hline Weight (kg) & $63.66(11.66)$ & $61.65(48.21-90.05)$ & $68.54(16.78)$ & $\begin{array}{c}64.60 \\
(46.72-103.20)\end{array}$ & 0.010 \\
\hline Height $(\mathrm{cm})$ & $164.64(6.00)$ & $\begin{array}{c}164.65 \\
(154.33-174.99)\end{array}$ & $164.64(6.56)$ & $\begin{array}{c}165.00 \\
(154.07-175.33)\end{array}$ & 0.995 \\
\hline $\mathrm{BMI}\left(\mathrm{kg} / \mathrm{m}^{2}\right)$ & $23.51(4.29)$ & $22.41(18.26-32.28)$ & $25.22(5.63)$ & $24.02(18.54-35.81)$ & 0.009 \\
\hline Fat mass $(\%)$ & $27.59(7.23)$ & $27.30(15.65-40.00)$ & $30.04(8.01)$ & $30.46(16.61-44.18)$ & 0.012 \\
\hline Bone mass (\%) & $13.26(3.97)$ & $14.34(6.66-18.59)$ & $12.52(3.78)$ & $13.32(6.72-17.98)$ & 0.139 \\
\hline Lean mass (\%) & 38.25 (7.55) & $37.82(27.65-54.13)$ & $36.54(8.35)$ & $36.44(22.93-51.44)$ & 0.089 \\
\hline Testosterone (nmol/L) & $0.97(0.49)$ & $0.90(0.03-1.81)$ & $1.33(0.61)$ & $1.25(0.45-2.55)$ & 0.000 \\
\hline Insulin (mUI/L) & $10.43(8.73)$ & $8.30(4.46-19.40)$ & $15.58(14.40)$ & $10.70(5.05-44.77)$ & 0.001 \\
\hline Glucose (mmol/L) & $83.08(9.75)$ & $82.00(72.00-98.00)$ & $86.56(18.52)$ & 85.00 (75.35-99.00) & 0.043 \\
\hline HOMA-IR & $2.18(1.97)$ & $1.71(0.87-4.36)$ & $3.32(3.10)$ & $2.29(1.02-9.95)$ & 0.000 \\
\hline TG (mg/dL) & $63.85(28.01)$ & $\begin{array}{c}58.00 \\
(33.00-119.00)\end{array}$ & $74.21(43.94)$ & $\begin{array}{c}61.50 \\
(34.35-162.60)\end{array}$ & 0.022 \\
\hline HDL-c (mg/dL) & $64.91(14.51)$ & $64.00(42.00-96.00)$ & $58.66(14.18)$ & $58.00(37.30-85.00)$ & 0.000 \\
\hline LDL-c (mg/dL) & $94.28(24.59)$ & $\begin{array}{c}94.00 \\
(59.00-132.00)\end{array}$ & $95.50(24.85)$ & $\begin{array}{c}94.00 \\
(60.30-131.70)\end{array}$ & 0.682 \\
\hline Total cholesterol & 171.99 (27.72) & $\begin{array}{c}169.00 \\
(130.00-218.00)\end{array}$ & $168.96(27.54)$ & $\begin{array}{c}169.00 \\
(130.35-219.30)\end{array}$ & 0.359 \\
\hline \multicolumn{3}{|c|}{ Hyperandrogenism + Oligo/amenorrhea } & \multicolumn{2}{|c|}{$14.2(8.1-20.3)$} & \\
\hline \multicolumn{3}{|c|}{ Hyperandrogenism + POM } & \multicolumn{2}{|c|}{$27.0(19.2-34.8)$} & \\
\hline \multicolumn{3}{|c|}{ Oligo/amenorrhea + POM } & \multicolumn{2}{|c|}{$15.9(9.5-22.3)$} & \\
\hline \multicolumn{3}{|c|}{ Hyperandrogenism +Oligo/amenorrhea + POM } & \multicolumn{2}{|c|}{$42.9(34.3-51.5)$} & \\
\hline
\end{tabular}

SD: standard deviation; 5-95: 5th-95th percentile; PCOS: polycystic ovarian syndrome. T-student/Mann-Whitney U-test compared with control participants. NS: non-significant; BMI: body mass index; TG: triglycerides; HDL-c: high-density lipoprotein cholesterol; LDL-c: low-density lipoprotein cholesterol; HOMA-IR (homeostasis model assessment of insulin resistance): (Insulin (mUI/L)X glucose $(\mathrm{mmol} / \mathrm{L})) / 22.5$; glucose: $\mathrm{mmol} / \mathrm{L}=\mathrm{mg} / \mathrm{dL} / 18$ (Matthews et al., 1985); POM: polycystic ovary morphology. Fenotype distribution expressed as percentage $(95 \% \mathrm{CI})$.

With regards to glycemic and lipid profiles, compared to control women, women with PCOS had significantly higher levels of testosterone (1.3 vs. $1.0 \mathrm{nmol} / \mathrm{L})$, insulin $(15.6$ vs. $10.4 \mathrm{mUI} / \mathrm{L})$, glucose (86.6 vs. $83.1 \mathrm{mg} / \mathrm{dL}$ ), HOMA-IR (3.3 vs. 2.2), and TG (74.2 vs. $63.8 \mathrm{mg} / \mathrm{dL})$, and lower values of HDL-c ( $58.7 \mathrm{mg} / \mathrm{dL}$ vs. 64.9$)$. No statistically significant differences in LDL-c and total cholesterol were found between groups (Table 1).

Univariate linear regression was used to evaluate the association between body composition (fat, bone, and lean mass) and lipid profile (Table 2). 
Table 2. Univariate linear regression analysis for individual body composition measures as predictors of lipid profile in the PCOS group and controls.

\begin{tabular}{|c|c|c|c|c|c|c|}
\hline & \multicolumn{2}{|c|}{ Fat Mass (\%) } & \multicolumn{2}{|c|}{ Bone Mass (\%) } & \multicolumn{2}{|c|}{ Lean Mass (\%) } \\
\hline & $\beta(95 \% \mathrm{CI})$ & $p$-Value & $\beta(95 \% \mathrm{CI})$ & $p$-Value & $\beta(95 \% \mathrm{CI})$ & $p$-Value \\
\hline \multicolumn{7}{|l|}{ TG } \\
\hline Control & $1.16(0.53$ to 1.78$)$ & 0.000 & $\begin{array}{c}-0.97(-2.16 \text { to } \\
0.22)\end{array}$ & 0.108 & $\begin{array}{c}-0.79(-1.41 \text { to } \\
-0.17)\end{array}$ & 0.012 \\
\hline PCOS & 1.71 (0.90 to 2.51$)$ & 0.000 & $\begin{array}{c}-1.14(-2.97 \text { to } \\
0.68)\end{array}$ & 0.218 & $\begin{array}{c}-1.33(-2.13 \text { to } \\
-0.54)\end{array}$ & 0.001 \\
\hline \multicolumn{7}{|c|}{ Total cholesterol } \\
\hline Control & $0.34(-0.31$ to 0.99$)$ & 0.305 & $\begin{array}{c}-1.20(-2.38 \text { to } \\
-0.02)\end{array}$ & 0.046 & $0.02(-0.61$ to 0.65$)$ & 0.952 \\
\hline PCOS & $0.55(-0.08$ to 1.19$)$ & 0.087 & $\begin{array}{c}-1.03(-2.38 \text { to } \\
0.31)\end{array}$ & 0.131 & $\begin{array}{c}-0.30(-0.91 \text { to } \\
0.32)\end{array}$ & 0.342 \\
\hline \multicolumn{7}{|l|}{$H D L-c$} \\
\hline Control & $\begin{array}{c}-0.80(-1.12 \text { to } \\
-0.49)\end{array}$ & 0.000 & $0.20(-0.42$ to 0.83$)$ & 0.515 & $0.68(0.37$ to 0.99$)$ & 0.000 \\
\hline PCOS & $\begin{array}{c}-0.74(-1.04 \text { to } \\
-0.45)\end{array}$ & 0.000 & $0.64(-0.04$ to 1.33$)$ & 0.064 & 0.55 (0.26 to 0.85$)$ & 0.000 \\
\hline \multicolumn{7}{|l|}{$L D L-c$} \\
\hline Control & 0.91 (0.36 to 1.47 ) & 0.002 & $\begin{array}{c}-1.21(-2.25 \text { to } \\
-0.17)\end{array}$ & 0.022 & $\begin{array}{c}-0.50(-1.05 \text { to } \\
0.04)\end{array}$ & 0.072 \\
\hline PCOS & 0.96 (0.39 to 1.53$)$ & 0.001 & $\begin{array}{c}-1.48(-2.72 \text { to } \\
-0.24)\end{array}$ & 0.019 & $\begin{array}{c}-0.58(-1.14 \text { to } \\
-0.02)\end{array}$ & 0.044 \\
\hline \multicolumn{7}{|l|}{$H O M A-I R$} \\
\hline Control & $0.06(0.02$ to 0.11$)$ & 0.010 & $\begin{array}{c}-0.17(-0.26 \text { to } \\
-0.08)\end{array}$ & 0.000 & $\begin{array}{c}-0.01(-0.06 \text { to } \\
0.03)\end{array}$ & 0.601 \\
\hline PCOS & 0.07 (0.00 to 0.14$)$ & 0.047 & $\begin{array}{c}-0.25(-0.39 \text { to } \\
-0.11)\end{array}$ & 0.001 & $\begin{array}{c}-0.01(-0.08 \text { to } \\
0.05)\end{array}$ & 0.712 \\
\hline
\end{tabular}

PCOS: polycystic ovarian syndrome; $\beta$ (95\% CI): unstandardized coefficients (95\% CI); BMI: body mass index; TG: triglycerides; HDL-c: high-density lipoprotein cholesterol; LDL-c: low-density lipoprotein cholesterol; HOMA-IR (homeostasis model assessment of insulin resistance.): (Insulin (mUI/L)X glucose (mmol/L)) /22.5; glucose: $\mathrm{mmol} / \mathrm{L}=\mathrm{mg} / \mathrm{dL} / 18$ (Matthews et al., 1985).

An increase in fat mass was associated with an increase in TG, LDL-c, and HOMA-IR and a decrease in HDL-c in both the PCOS and control groups. On the other hand, an increase in bone mass was related to a decrease in LDL-c and HOMA-IR in both groups. We only found a negative association between total cholesterol and bone mass in the control group. Finally, an increase in lean mass was associated with a decrease in TG levels and an increase in HDL-c in both groups, and with a decrease in LDL-c in the PCOS group (Table 2).

Multivariate linear regression analyses were performed to assess the independent relation of body composition (fat, bone, and lean mass) on lipid profile after adjusting for serum testosterone concentrations, age, and PCOS condition (Table 3). Body composition evaluated by anthropometry proved to be a predictive factor for alterations in lipid metabolism in all women. A higher fat mass predicted higher TG levels $(\beta=1.29,95 \% \mathrm{CI}$ : 0.77 to $1.80, p<0.001)$, higher LDL-c $(\beta=0.66,95 \%$ CI: 0.26 to $1.06, p=0.001)$, lower HDL-c ( $\beta=-0.81,95 \%$ CI: -1.04 to $-0.59, p<0.001$ ), and higher HOMA-IR levels ( $\beta=0.07,95 \%$ CI: 0.03 to $0.11, p=0.001$ ). 
Table 3. Multivariate linear regression analysis for individual body composition measures as predictors of lipid profile in PCOS $(n=126)$ and controls $(n=159)$.

\begin{tabular}{|c|c|c|c|c|c|c|}
\hline & \multicolumn{2}{|c|}{ Fat Mass (\%) } & \multicolumn{2}{|c|}{ Bone Mass (\%) } & \multicolumn{2}{|c|}{ Lean Mass (\%) } \\
\hline & $\beta(95 \% \mathrm{CI})$ & $p$-Value & $\beta(95 \% \mathrm{CI})$ & $p$-Value & $\beta(95 \% \mathrm{CI})$ & $p$-Value \\
\hline \multicolumn{7}{|l|}{ Triglyceride } \\
\hline $\begin{array}{l}\text { Body composition } \\
\text { indicator }\end{array}$ & $1.29(0.77$ to 1.80$)$ & 0.000 & $\begin{array}{c}-0.78(-1.81 \text { to } \\
0.25)\end{array}$ & 0.136 & $\begin{array}{c}-0.96(-1.46 \text { to } \\
-0.47)\end{array}$ & 0.000 \\
\hline PCOS (Yes) & $\begin{array}{c}7.04(-1.25 \text { to } \\
15.33)\end{array}$ & 0.096 & 10.56 (2.02 to 19.10$)$ & 0.016 & 9.29 (0.97 to 17.62$)$ & 0.029 \\
\hline Testosterone & $\begin{array}{c}-2.22(-9.30 \text { to } \\
4.87)\end{array}$ & 0.538 & $\begin{array}{c}-0.39(-7.85 \text { to } \\
7.08)\end{array}$ & 0.919 & $\begin{array}{c}-3.00(-10.27 \text { to } \\
4.26)\end{array}$ & 0.416 \\
\hline Age & $0.70(-0.03$ to 1.43$)$ & 0.061 & 1.19 (0.45 to 1.92$)$ & 0.002 & 0.88 (0.14 to 1.62$)$ & 0.020 \\
\hline \multicolumn{7}{|l|}{ Total cholesterol } \\
\hline $\begin{array}{l}\text { Body composition } \\
\text { indicator }\end{array}$ & $0.10(-0.35$ to 0.55$)$ & 0.653 & $\begin{array}{c}-0.89(-1.74 \text { to } \\
-0.03)\end{array}$ & 0.043 & $0.13(-0.30$ to 0.55$)$ & 0.565 \\
\hline PCOS (Yes) & $\begin{array}{c}3.64(-3.64 \text { to } \\
10.93)\end{array}$ & 0.326 & $\begin{array}{c}2.95(-4.18 \text { to } \\
10.08)\end{array}$ & 0.416 & $\begin{array}{c}4.28(-2.90 \text { to } \\
11.46)\end{array}$ & 0.241 \\
\hline Testosterone & $\begin{array}{c}-1.44(-7.67 \text { to } \\
4.78)\end{array}$ & 0.648 & $\begin{array}{c}-0.41(-6.65 \text { to } \\
5.82)\end{array}$ & 0.897 & $\begin{array}{c}-1.13(-7.40 \text { to } \\
5.13)\end{array}$ & 0.722 \\
\hline Age & 1.70 (1.06 to 2.35$)$ & 0.000 & 1.70 (1.09 to 2.32 ) & 0.000 & 1.79 (1.16 to 2.43$)$ & 0.000 \\
\hline \multicolumn{7}{|l|}{$H D L-c$} \\
\hline $\begin{array}{l}\text { Body composition } \\
\text { indicator }\end{array}$ & $\begin{array}{c}-0.81(-1.04 \text { to } \\
-0.59)\end{array}$ & 0.000 & $0.35(-0.12$ to 0.82$)$ & 0.139 & $0.64(0.42$ to 0.86$)$ & 0.000 \\
\hline PCOS (Yes) & $\begin{array}{c}-2.55(-6.19 \text { to } \\
1.09)\end{array}$ & 0.169 & $\begin{array}{c}-4.97(-8.90 \text { to } \\
-1.04)\end{array}$ & 0.013 & $\begin{array}{c}-3.93(-7.63 \text { to } \\
-0.23)\end{array}$ & 0.037 \\
\hline Testosterone & $\begin{array}{c}-0.24(-3.34 \text { to } \\
2.85)\end{array}$ & 0.877 & $\begin{array}{c}-1.23(-4.66 \text { to } \\
2.20)\end{array}$ & 0.480 & $0.33(-2.88$ to 3.55$)$ & 0.838 \\
\hline Age & $0.22(-0.10$ to 0.54$)$ & 0.174 & $\begin{array}{c}-0.10(-0.43 \text { to } \\
0.24)\end{array}$ & 0.574 & $0.12(-0.21$ to 0.45$)$ & 0.473 \\
\hline \multicolumn{7}{|l|}{$L D L-C$} \\
\hline $\begin{array}{l}\text { Body composition } \\
\text { indicator }\end{array}$ & $0.66(0.26$ to 1.06$)$ & 0.001 & $\begin{array}{c}-1.09(-1.86 \text { to } \\
-0.32)\end{array}$ & 0.006 & $\begin{array}{c}-0.32(-0.71 \text { to } \\
0.06)\end{array}$ & 0.098 \\
\hline PCOS (Yes) & $\begin{array}{c}5.04(-1.42 \text { to } \\
11.51)\end{array}$ & 0.126 & $\begin{array}{c}6.03(-0.39 \text { to } \\
12.44)\end{array}$ & 0.065 & $6.61(0.14$ to 13.08$)$ & 0.045 \\
\hline Testosterone & $\begin{array}{c}-0.88(-6.39 \text { to } \\
4.63)\end{array}$ & 0.753 & $0.80(-4.79$ to 6.39$)$ & 0.779 & $\begin{array}{c}-0.99(-6.62 \text { to } \\
4.64)\end{array}$ & 0.730 \\
\hline Age & $1.36(0.79$ to 1.93$)$ & 0.000 & 1.58 (1.03 to 2.13$)$ & 0.000 & 1.51 (0.94 to 2.08$)$ & 0.000 \\
\hline \multicolumn{7}{|l|}{ HOMA-IR } \\
\hline $\begin{array}{l}\text { Body composition } \\
\text { indicator }\end{array}$ & 0.07 (0.03 to 0.11$)$ & 0.001 & $\begin{array}{c}-0.20(-0.28 \text { to } \\
-0.12)\end{array}$ & 0.000 & $\begin{array}{c}-0.02(-0.06 \text { to } \\
0.03)\end{array}$ & 0.474 \\
\hline PCOS (Yes) & 0.79 (0.10 to 1.48$)$ & 0.025 & $0.78(0.11$ to 1.44$)$ & 0.022 & $1.00(0.30$ to 1.69$)$ & 0.005 \\
\hline Testosterone & $\begin{array}{c}-0.40(-1.00 \text { to } \\
0.19)\end{array}$ & 0.184 & $\begin{array}{c}-0.15(-0.74 \text { to } \\
0.43)\end{array}$ & 0.605 & $\begin{array}{c}-0.38(-0.99 \text { to } \\
0.23)\end{array}$ & 0.224 \\
\hline Age & $\begin{array}{c}-0.03(-0.09 \text { to } \\
0.03)\end{array}$ & 0.389 & $\begin{array}{c}-0.01(-0.07 \text { to } \\
0.05)\end{array}$ & 0.751 & $0.00(-0.07$ to 0.06$)$ & 0.881 \\
\hline
\end{tabular}

PCOS: polycystic ovarian syndrome; $\beta$ (95\% CI): unstandardized coefficients (95\% CI); BMI: body mass index; TG: triglycerides; HDL-c: high-density lipoprotein cholesterol; LDL-c: low-density lipoprotein cholesterol; HOMA-IR (homeostasis model assessment of insulin resistance): (Insulin (mUI/L)X glucose $(\mathrm{mmol} / \mathrm{L})$ )/22.5; glucose: $\mathrm{mmol} / \mathrm{L}=\mathrm{mg} / \mathrm{dL} / 18$ (Matthews et al. 1985).

Regarding bone mass, higher percentages were associated with lower total cholesterol levels $(\beta=-0.89,95 \% \mathrm{CI}:-1.74$ to $-0.03, p=0.043)$, lower LDL-c $(\beta=-1.09,95 \% \mathrm{CI}$ : -1.86 to $-0.392 p=0.006)$, and lower HOMA-IR $(\beta=-0.20,95 \% \mathrm{CI}:-0.28$ to -0.12 , $p<0.001)$. Bone mass was not associated with TG in multivariate models after adjusting for age, testosterone, and PCOS status (Table 3). On the other hand, lean mass was negatively associated with TG $(\beta=-0.96,95 \% \mathrm{CI}:-1.46$ to $-0.47, p<0.001)$ and positively with HDL-c $(\beta=0.64,95 \%$ CI: 0.42 to $0.86, p<0.001)$. Furthermore, total cholesterol, LDL-c, and HOMA-IR levels did not differ depending on lean mass values. 
These multivariate analyses also showed that PCOS lost its significant association with TG, HDL-c, and LDL-c after adjustment for fat mass. However, PCOS remained associated with higher HOMA-IR regardless of the effect of body composition. Neither crude nor adjusted significant associations were found between total cholesterol and PCOS status.

Finally, we found that older age was related to higher total cholesterol and higher LDL-c (independent of body composition, PCOS condition, and testosterone levels). In order to evaluate the potential influence of PCOS condition on the association of age with metabolic disorders, linear regression models with interaction effects were carried out. TG, total cholesterol, and LDL-c were considered dependent variables, and PCOS condition and age were explanatory variables. The interaction terms were statistically significant in these models, showing the influence of PCOS condition on the association of aging with TG, total cholesterol, and LDL-c, being more accentuated for those who suffered from PCOS Appendix A (Table A1).

\section{Discussion}

Our results highlight the importance of body composition (especially the predominant percentage of fat mass) as an anthropometrical characteristic of PCOS, and the relationship of fat mass with worse metabolic profile. Even more, PCOS was related to worse HOMA-IR independent of body composition. Other metabolic parameters (higher total cholesterol and LDL-c) should be especially monitored in women with PCOS since they easily worsened with age compared to controls.

Overall, we found that there were differences in body composition estimated by anthropometric method between women with PCOS and controls (percentage of fat mass: $30.2 \%$ PCOS vs. $27.6 \%$ controls). These results are in agreement with Satyaraddi et al. [33], who reported that women with PCOS had higher total body fat when compared to their age- and BMI-matched controls, and Dou et al. [34], who established a diagnostic cutoff point over $29 \%$ of fat mass for PCOS condition independent of the methodology employed to quantify adiposity [35-37]. Regarding the percentage of lean mass, we did not find statistically significant differences. However, other authors have reported higher lean mass in women with PCOS in relation to higher androgens levels $[33,38,39]$. These differences in body composition could be explained by the abnormal endocrine milieu (hyperandrogenism and hyperestrogenemia) that characterizes PCOS. Even though androgens are known to increase muscle mass, these steroids seem to have a limited effect on lean muscle mass in women with PCOS [40,41]. Similarly, no significant differences in bone mass between PCOS and controls were seen in our study, although women with PCOS tended to present lower percentages. This aspect also remains unclear in the literature. Several studies have reported lower bone mass in PCOS evaluated by DEXA [36,42,43] or CAT scan [44]. On the other hand, other authors found that women with PCOS presented greater bone density using the DEXA methodology [45-47].

Regarding hormonal and biochemical parameters, we found significant differences between PCOS and controls. Obesity and PCOS are linked to similar metabolic disorders (hyperandrogenism, insulin resistance). In addition, several studies have shown that the incidence rate of obesity in women with PCOS is 30-70\% [4,5], higher than in non-PCOS women. In a recent metanalysis, Li et al. [48] concluded that metabolic disorders in adolescent women with PCOS are worsened by concomitant obesity. As a result, obesity in women with PCOS leads to worsening their endocrine, reproductive, and metabolic disturbances [7]. Dou et al. [34] compared BMI, abdominal circumference, and fat mass measured by impedanciometry and concluded that the percentage of fat mass was the best predictor of insulin resistance in women with PCOS. Our results in Table 2 show that the percentage of fat mass predicted higher TG, LDL-c, and HOMA-IR and lower HDL-c levels in both groups, not only in PCOS. The question arises whether body composition (specifically the percentage of fat mass) is an independent variable apart from PCOS condition for a worse metabolic profile in these women. In the multivariate analysis (Table 3), we found that only higher HOMA-IR remained associated with PCOS regardless of the effect of body 
composition. Other authors have suggested that the metabolic impairment in women with PCOS seems to not only be dependent on the total fat mass content and body weight but might also be ascribed to the androgen excess [49]. We discarded this possibility because we included testosterone in our model, showing the effect of PCOS condition by itself. Our results suggest that both body composition and PCOS could predict metabolic disorders (especially insulin resistance) independently. This means that both PCOS and fat mass are independent and summative risk factors for higher HOMA, with the PCOS condition being the main risk factor when both coexist. This result is in agreement with the conclusion of a metanalysis about insulin resistance on women with PCOS, which concluded that BMI exacerbates insulin resistance in PCOS and has a disproportionately greater impact in PCOS than in controls [50]. Recently, it has been reported that the usefulness of the neck circumference is a good predictor for insulin resistance in women with PCOS [51].

Regarding bone mass, in our study, the higher percentages were associated with lower total cholesterol, lower LDL-c, and insulin resistance (HOMA). Lower HOMA-IR remained associated with PCOS regardless of bone mass. This means that both PCOS and bone mass are independent and opposite risk factors for higher HOMA, with the PCOS condition being the main risk factor when both coincide. It is unknown whether bone metabolism plays a pivotal role as mediator in atherosclerosis [52,53] or whether bone loss is just a marker of systemic inflammation [54]. Other authors found an association between inflammatory markers, including insulin resistance, suggesting that a higher degree of inflammation might be in part responsible for the deterioration of bone health [55]. In our study, higher lean mass percentages predicted a better metabolic profile (lower TG and higher HDL-c), also modulated by the PCOS condition. This means that both PCOS and lean mass are independent and opposite risk factors for higher HOMA, with the PCOS condition being the main risk factor when both concur. Some authors are in agreement with this result, suggesting that the negative effect of fat mass on the metabolic risk could be counterbalanced by an increment of lean body mass and the net effect could be estimated by calculating the fat/lean body mass ratio $[37,56]$. By contrast, Mario et al. reported that an increase in lean mass in anovulatory PCOS appears to be associated with insulin resistance and TG levels [57]. Other authors also reported that lean mass correlated directly with HOMA independent of fat mass in women with PCOS $[58,59]$.

In addition, we analyzed the role of the women's age as a predictor of metabolic parameters. In our study, women's age was related to higher total cholesterol and LDL-c (regardless of body composition and independent of PCOS condition). Finally, we explored the influence of the PCOS condition (vs. control women) in the association of aging with metabolic disorders. We found worse metabolic parameters for women who suffer from PCOS. This is consistent with the fact that women with PCOS are more likely to develop long-term complications if they are obese, and these comorbidities increase exponentially and faster with age than in the general population $[41,60]$.

In conclusion, obesity in women with PCOS leads to worsening their endocrine, reproductive, and metabolic disturbances. It is important to analyze and offer accessible and reliable procedures to calculate fat mass and to diagnose its excess early. Previous studies analyzing fat mass and metabolic consequences used mainly expensive procedures not available in many settings (DEXA [27], bioelectrical impedance body composition analyzer [28], MRI, or CAT scan). In contrast, anthropometric assessment is a widely used, low-technology procedure. Skinfold caliper measurement as an indirect anthropometric technique is the most cost-effective method due to its validity and reliability with minimal equipment cost and technical training, enabling the estimation of whole-body fat.

Our findings suggest that both body composition (measured by skinfold thickness) and PCOS condition could predict metabolic disorders (especially insulin resistance) independently. Thus, offering easy and accessible ways to measure fat mass in different clinical areas could help to prevent obesity and its consequences. In this way, body composition measured by skinfold thickness is the most cost-effective method and could have an essential role in the screening and monitoring for adverse metabolic disorders and 
provide prevention care in women with PCOS in different clinical areas, mainly in primary health care. Lastly, our study presents some limitations. Measurement and selection bias must always be considered [61]. However, the controls were women attending the public hospital department in the same study period, and they came from the same population as the cases. Misclassification of PCOS status may have occurred, but if present, it would have contributed to underestimating the true magnitude of the relationship. In the same way, differences in age were present in both groups, but the PCOS group was included in multivariable models along with age and testosterone to assess potential confounding, as well as possible interactions between them. Further studies will be required to determine the time of onset of this adverse body composition, including whether it may be programmed in utero and even the onset of the metabolic alterations. As strengths, the examiners were unaware of the women's final diagnosis of PCOS (cases or controls). Even more, we independently analyzed the association between body composition and PCOS using an anthropometry method and taking into account testosterone levels and age as confounders to predict the metabolic profile.

\section{Conclusions}

Body composition estimated by anthropometry, especially fat mass, is related to worse metabolic profile in PCOS. Even more, PCOS is related to worse HOMA-IR independent of body composition. These findings should be born in mind in terms of prevention during the clinical management of these women. We propose anthropometric measurement according to the ISAK as an easy, cost-effective, and reliable screening and monitoring method available in different clinical areas-mainly in primary health care-for adverse metabolic disorders in PCOS. Therapeutic intervention combined with lifestyle modifications may provide better treatment for PCOS, as they could be able to reduce fat mass percentages and decrease the risk for long-term morbidities that depend on metabolic profiles.

Supplementary Materials: The following are available online at https:/ /www.mdpi.com/article/10 .3390/app11125395/s1, Figure S1: ISAK full proforma.

Author Contributions: Authors' roles. A.M.T.-C., J.M. and M.L.S.-F. were involved in the study conception and design. A.I.H.-P., I.G.-C., M.T.P.-S., and M.L.S.-F. were involved in the study execution and the acquisition of data. J.J.A.-G., M.L.S.-F., M.T.P.-S., J.M. and A.M.T.-C. contributed to the data analysis and interpretation. M.L.S.-F., J.J.A.-G., M.T.P.-S., A.I.H.-P., I.G.-C., J.M. and A.M.T.-C. drafted the manuscript. All authors provided substantial intellectual contributions. All authors have read and agreed to the published version of the manuscript.

Funding: This work was supported by the Ministry of Economy and Competitiveness ISCIII (AES), grant no. PI13/01237 and The Seneca Foundation, Murcia Regional Agency of Science and Technology, grant no. 19443/PI/14.

Institutional Review Board Statement: This study was conducted in accordance with the principles of the Declaration of Helsinki with regards to studies involving human subjects, and also in line with Law 14/2007 for biomedical research. The principles of confidentiality and anonymity in the treatment of the data and presentation of the results were respected at all times, in line with legislation (EU) 2016/679 of the European Parliament and Council on 27 April 2016 concerning the protection of natural persons in terms of the processing of personal data and its free movement of such data. This study was approved by the Ethics Research Committee of the HCUVA (no. 770/2013. approved 3 October 2013).

Informed Consent Statement: Informed consent was obtained from all subjects involved in the study. Written informed consent was obtained from the patients to publish this paper.

Data Availability Statement: The data sets generated and/or analyzed during the current study are available from the corresponding author on reasonable request.

Conflicts of Interest: The authors declare no conflict of interest. 


\section{Appendix A}

Table A1. Interaction effects of age and PCOS condition on lipid profile.

\begin{tabular}{cccccccccc}
\hline & \multicolumn{3}{c}{ Triglyceride } & \multicolumn{3}{c}{ Total Cholesterol } & \multicolumn{2}{c}{ LDL-c } \\
\cline { 2 - 10 } & $\beta$ & $\begin{array}{c}\text { Std. } \\
\text { Error }\end{array}$ & $\boldsymbol{p}$-Value & $\boldsymbol{\beta}$ & $\begin{array}{c}\text { Std. } \\
\text { Error }\end{array}$ & $\boldsymbol{p}$-Value & $\boldsymbol{\beta}$ & $\begin{array}{c}\text { Std. } \\
\text { Error }\end{array}$ & $\boldsymbol{p}$-Value \\
\hline Age & 0.566 & 0.478 & 0.237 & 1.098 & 0.349 & 0.002 & 1.107 & 0.314 \\
PCOS (Yes) & -35.917 & 22.78 & 0.116 & -46.044 & 16.623 & 0.006 & -27.416 & 15.003 & 0.069 \\
$\begin{array}{c}\text { PCOS (Yes) } \\
\text { X Age }\end{array}$ & 1.758 & 0.781 & 0.025 & 1.703 & 0.57 & 0.003 & 1.183 & 0.515 & 0.022 \\
\hline
\end{tabular}

\section{References}

1. Jones, M.R.; Goodarzi, M.O. Genetic determinants of polycystic ovary syndrome: Progress and future directions. Fertil. Steril. 2016, 106, 25-32. [CrossRef]

2. Carmina, E.; Rosato, F.; Jannì, A.; Rizzo, M.; Longo, R.A. Relative prevalence of different androgen excess disorders in 950 women referred because of clinical hyperandrogenism. J. Clin. Endocrinol. Metab. 2006, 91, 2-6. [CrossRef]

3. Azziz, R.; Woods, K.S.; Reyna, R.; Key, T.J.; Knochenhauer, E.S.; Yildiz, B.O. The prevalence and features of the polycystic ovary syndrome in an unselected population. J. Clin. Endocrinol. Metab. 2004, 89, 2745-2749. [CrossRef]

4. Lizneva, D.; Kirubakaran, R.; Mykhalchenko, K.; Suturina, L.; Chernukha, G.; Diamond, M.P.; Azziz, R. Phenotypes and body mass in women with polycystic ovary syndrome identified in referral versus unselected populations: Systematic review and meta-analysis. Fertil. Steril. 2016, 106, 1510-1520.e2. [CrossRef] [PubMed]

5. Fauser, B.C.J.M.; Bouchard, P. Uncertainty remains in women with PCOS regarding the increased incidence of cardiovascular disease later in life, despite the indisputable presence of multiple cardiovascular risk factors at a young age. J. Clin. Endocrinol. Metab. 2011, 96, 3675-3677. [CrossRef] [PubMed]

6. Barry, J.A.; Azizia, M.M.; Hardiman, P.J. Risk of endometrial, ovarian and breast cancer in women with polycystic ovary syndrome: A systematic review and meta-analysis. Hum. Reprod. Update 2014, 20, 748-758. [CrossRef]

7. Ehrmann, D.A. Polycystic ovary syndrome. N. Engl. J. Med. 2005, 352, 1223-1236. [CrossRef]

8. Esmaeilzadeh, S.; Andarieh, M.G.; Ghadimi, R.; Delavar, M.A. Body mass index and gonadotropin hormones (LH \& FSH) associate with clinical symptoms among women with polycystic ovary syndrome. Glob. J. Health Sci. 2014, 7, 101-106.

9. Sahin, S.B.; Durakoglugil, T.; Ayaz, T.; Sahin, O.Z.; Durakoglugil, E.; Sumer, F.; Aktas, E.; Alyildiz, N. Evaluation of paraand perirenal fat thickness and its association with metabolic disorders in polycystic ovary syndrome. Endocr. Pract. 2015, 21, 878-886. [CrossRef]

10. Crosignani, P.G.; Colombo, M.; Vegetti, W.; Somigliana, E.; Gessati, A.; Ragni, G. Overweight and obese anovulatory patients with polycystic ovaries: Parallel improvements in anthropometric indices, ovarian physiology and fertility rate induced by diet. Hum. Reprod. 2003, 18, 1928-1932. [CrossRef] [PubMed]

11. Legro, R.S.; Arslanian, S.A.; Ehrmann, D.A.; Hoeger, K.M.; Murad, M.H.; Pasquali, R.; Welt, C.K. Diagnosis and treatment of polycystic ovary syndrome: An endocrine society clinical practice guideline. J. Clin. Endocrinol. Metab. 2013, 98, 4565-4592. [CrossRef]

12. Rotterdam ESHRE/ASRM-Sponsored PCOS consensus workshop group. Revised 2003 consensus on diagnostic criteria and long-term health risks related to polycystic ovary syndrome (PCOS). Hum. Reprod. 2004, 19, 41-47. [CrossRef]

13. Lo, J.C.; Feigenbaum, S.L.; Yang, J.; Pressman, A.R.; Selby, J.V.; Go, A.S. Epidemiology and adverse cardiovascular risk profile of diagnosed polycystic ovary syndrome. J. Clin. Endocrinol. Metab. 2006, 91, 1357-1363. [CrossRef] [PubMed]

14. Aboeldalyl, S.; James, C.; Seyam, E.; Ibrahim, E.M.; Shawki, H.E.D.; Amer, S. The role of Chronic Inflammation in Polycystic Ovarian Syndrome-A Systematic Review and Meta-Analysis. Int. J. Mol. Sci. 2021, 22, 2734. [CrossRef]

15. Krentowska, A.; Kowalska, I. Metabolic Syndrome and Its Components in Different Phenotypes of Polycystic Ovary Syndrome. Available online: https:// pubmed.ncbi.nlm.nih.gov/33988288/ (accessed on 31 May 2021).

16. Zaadstra, B.M.; Seidell, J.C.; Van Noord, P.A.; te Velde, E.R.; Habbema, J.D.; Vrieswijk, B.; Karbaat, J. Fat and female fecundity: Prospective study of effect of body fat distribution on conception rates. BMJ 1993, 306, 484-487. [CrossRef]

17. Luke, B. Adverse effects of female obesity and interaction with race on reproductive potential. In Fertility and Sterility; Elsevier Inc.: Amdsterdam, The Netherlands, 2017; Volume 107, pp. 868-877. Available online: https://pubmed.ncbi.nlm.nih.gov/28366413/ (accessed on 31 May 2021).

18. Broughton, D.E.; Moley, K.H. Obesity and Female Infertility: Potential Mediators of Obesity's Impact. In Fertility and Sterility; Elsevier Inc.: Amdsterdam, The Netherlands, 2017; Volume 107, pp. 840-847. Available online: https:/ / pubmed.ncbi.nlm.nih. gov/28292619/ (accessed on 31 May 2021).

19. Heath, B.H. Need for modification of somatotype methodology. Am. J. Phys. Anthropol. 1963, 21, 227-233. [CrossRef] [PubMed]

20. Heath, B.H.; Carter, J.E. A comparison of somatotype methods. Am. J. Phys. Anthropol. 1966, 24, 87-99. [CrossRef] [PubMed]

21. Heath, B.H.; Carter, J.E. A modified somatotype method. Am. J. Phys. Anthropol. 1967, 27, 57-74. [CrossRef]

22. Carter, J.E.L.; Honeyman Heath, B. Somatotyping: Development and Applications; Cambridge University Press: New York, NY, USA, 1990. 
23. Amaral, T.F.; Teresa Restivo, M.; Guerra, R.S.; Marques, E.; Chousal, M.F.; Mota, J. Accuracy of a Digital Skinfold System for Measuring Skinfold Thickness and Estimating Body Fat. Br. J. Nutr. 2011, 105, 478-484. Available online: https://pubmed.ncbi. nlm.nih.gov/21134326/ (accessed on 30 November 2020). [CrossRef]

24. Martín, V.G.J.A.M. Medición de la Grasa Corporal Mediante Impedancia Bioeléctrica, Pliegues Cutáneos y Ecuaciones a Partir De Medidas Antropométricas. In Análisis Comparativo; Revista Española de Salud Pública: Madrid, Spain, 2001; Volume 75, pp. 221-236. Available online: http:/ / scielo.isciii.es/scielo.php?script=sci_arttext\&pid=S1135-57272001000300006 (accessed on 13 December 2020).

25. Geronikolou, S.A.; Bacopoulou, F.; Cokkinos, D. Bioimpedance measurements in adolescents with polycystic ovary syndrome: A pilot study. In Advances in Experimental Medicine and Biology; Springer LLC.: New York, NY, USA, 2017; pp. $291-299$.

26. Marroquín Rodríguez, A.L.; Cervante, T.J.M.; Morales Cortés, L.; Garza Villarreal, E.A. Somatotipo de la Mujer con Síndrome de Ovario Poliquístico. Somatotype of Women with Polycystic Ovary Syndrome; FML: Valencia, Spain, 2012; Volume 16, 4p.

27. Sánchez-Ferrer, M.L.; Mendiola, J.; Hernández-Peñalver, A.I.; Corbalán-Biyang, S.; Carmona-Barnosi, A.; Prieto-Sánchez, M.T.; Nieto, A.; Torres-Cantero, A.M. Presence of polycystic ovary syndrome is associated with longer anogenital distance in adult Mediterranean women. Hum. Reprod. 2017, 32, 2315-2323. [CrossRef]

28. Ferriman, D.; Gallwey, J.D. Clinical assessment of body hair growth in women. J. Clin. Endocrinol. Metab. 1961, 21, 1440-1447. [CrossRef]

29. Afifi, L.; Saeed, L.; Pasch, L.A.; Huddleston, H.G.; Cedars, M.I.; Zane, L.T.; Shinkai, K. Association of ethnicity, Fitzpatrick skin type, and hirsutism: A retrospective cross-sectional study of women with polycystic ovarian syndrome. Int. J. Women Dermatol. 2017, 3, 37-43. Available online: https://pubmed.ncbi.nlm.nih.gov/28492053/ (accessed on 28 May 2021). [CrossRef]

30. Conway, G.; Dewailly, D.; Diamanti-Kandarakis, E.; Escobar-Morreale, H.F.; Franks, S.; Gambineri, A.; Kelestimur, F.; Macut, D.; Micic, D.; Paquali, R.; et al. The polycystic ovary syndrome: A position statement from the European Society of Endocrinology. Eur. J. Endocrinol. 2014, 171, P1-P29. Available online: https:/ / pubmed.ncbi.nlm.nih.gov/24849517/ (accessed on 28 May 2021). [CrossRef] [PubMed]

31. Matthews, D.R.; Hosker, J.P.; Rudenski, A.S.; Naylor, B.A.; Treacher, D.F.; Turner, R.C. Homeostasis model assessment: Insulin resistance and beta-cell function from fasting plasma glucose and insulin concentrations in man. Diabetologia 1985, 28, 412-419. [CrossRef] [PubMed]

32. Jackson, A.S.; Pollock, M.L.; Ward, A. Generalized equations for predicting body density of women. Med. Sci. Sports Exerc. 1980, 12, 175-181. [CrossRef] [PubMed]

33. Satyaraddi, A.; Cherian, K.; Kapoor, N.; Kunjummen, A.; Kamath, M.; Thomas, N.; Paul, T. Body composition, metabolic characteristics, and insulin resistance in obese and nonobese women with polycystic ovary syndrome. J. Hum. Reprod. Sci. 2019, $12,78-84$.

34. Dou, P.; Ju, H.; Shang, J.; Li, X.; Xue, Q.; Xu, Y.; Guo, X. Application of receiver operating characteristic curve in the assessment of the value of body mass index, waist circumference and percentage of body fat in the Diagnosis of Polycystic Ovary Syndrome in childbearing women. J. Ovarian Res. 2016, 9, 51. [CrossRef]

35. Arpaci, D.; Gurkan Tocoglu, A.; Yilmaz, S.; Ergenc, H.; Tamer, A.; Keser, N.; Gunduz, H. The relationship between epicardial fat tissue thickness and visceral adipose tissue in lean patients with polycystic ovary syndrome. J. Ovarian Res. 2015, 8, 71. [CrossRef]

36. Kirchengast, S.; Huber, J. Body composition characteristics and body fat distribution in lean women with polycystic ovary syndrome. Hum. Reprod. 2001, 16, 1255-1260. [CrossRef]

37. Ezeh, U.; Pall, M.; Mathur, R.; Azziz, R. Association of fat to lean mass ratio with metabolic dysfunction in women with polycystic ovary syndrome. Hum. Reprod. 2014, 29, 1508-1517. [CrossRef]

38. Douchi, T.; Oki, T.; Yamasaki, H.; Kuwahata, R.; Nakae, M.; Nagata, Y. Relationship of androgens to muscle size and bone mineral density in women with polycystic ovary syndrome. Obstet. Gynecol. 2001, 98, 445-449. [PubMed]

39. Kogure, G.S.; Silva, R.C.; Picchi Ramos, F.K.; Miranda-Furtado, C.L.; Lara, L.A.D.S.; Ferriani, R.A.; Dos Reis, R.M. Women with polycystic ovary syndrome have greater muscle strength irrespective of body composition. Gynecol. Endocrinol. 2015, 31, 237-242. Available online: https:/ / pubmed.ncbi.nlm.nih.gov/25430509/ (accessed on 31 May 2021). [CrossRef] [PubMed]

40. Rariy, C.M.; Ratcliffe, S.J.; Weinstein, R.; Bhasin, S.; Blackman, M.R.; Cauley, J.A.; Robbins, J.; Zmuda, J.M.; Harris, T.B.; Cappola, A.R. Higher serum free testosterone concentration in older women is associated with greater bone mineral density, lean body mass, and total fat mass: The cardiovascular health study. J. Clin. Endocrinol. Metab. 2011, 96, 989-996. [CrossRef] [PubMed]

41. Goodman, N.F.; Cobin, R.H.; Futterweit, W.; Glueck, J.S.; Legro, R.S.; Carmina, E. American association of clinical endocrinologists, American college of endocrinology, and androgen excess and pcos society disease state clinical review: Guide to the best practices in the evaluation and treatment of polycystic ovary syndrome-Part 2. Endocrine Practice. Am. Assoc. Clin. Endocrinol. 2015, $21,1415-1426$.

42. Katulski, K.; Slawek, S.; Czyzyk, A.; Podfigurna-Stopa, A.; Paczkowska, K.; Ignaszak, N.; Podkowa, N.; Meczekalski, B. Bone mineral density in women with polycystic ovary syndrome. J. Endocrinol. Investig. 2014, 37, 1219-1224. [CrossRef] [PubMed]

43. Ganie, M.A.; Chakraborty, S.; Sehgal, A.; Sreejith, M.; Kandasamy, D.; Jana, M.; Rashid, A. Bone mineral density is unaltered in women with polycystic ovary syndrome. Horm. Metab. Res. 2018, 50, 754-760. [CrossRef]

44. Prior, J.C.; Vigna, Y.M.; Schechter, M.T.; Burgess, A.E. Spinal bone loss and ovulatory disturbances. N. Engl. J. Med. 1990, 323, 1221-1227. [CrossRef] 
45. Zborowski, J.V.; Cauley, J.A.; Talbott, E.O.; Guzick, D.S.; Winters, S.J. Clinical Review 116: Bone mineral density, androgens, and the polycystic ovary: The complex and controversial issue of androgenic influence in female bone. J. Clin. Endocrinol. Metab. 2000, 85, 3496-3506. [CrossRef]

46. Chen, J.F.; Lin, P.W.; Tsai, Y.R.; Yang, Y.C.; Kang, H.Y. Androgens and Androgen Receptor Actions on Bone Health and Disease: From Androgen Deficiency to Androgen Therapy; NLM: Bethseda, MD, USA, 2019; Volume 8, Available online: https://pubmed.ncbi.nlm. nih.gov/31731497/ (accessed on 31 May 2021).

47. McBreairty, L.E.; Zello, G.A.; Gordon, J.J.; Serrao, S.B.; Pierson, R.A.; Chizen, D.R.; Chilibeck, P.D. Women with Polycystic Ovary Syndrome have Comparable Hip Bone Geometry to Age-Matched Control Women. J. Clin. Densitom. 2018, 21, 54-60. Available online: https: / pubmed.ncbi.nlm.nih.gov/28034591/ (accessed on 31 May 2021). [CrossRef]

48. Li, L.; Feng, Q.; Ye, M.; He, Y.; Yao, A.; Shi, K. Metabolic effect of obesity on polycystic ovary syndrome in adolescents: A meta-analysis. J. Obstet. Gynaecol. 2017, 37, 1036-1047. [CrossRef]

49. Condorelli, R.A.; Calogero, A.E.; Di Mauro, M.; Mongioi', L.M.; Cannarella, R.; Rosta, G.; La Vignera, S. Androgen excess and metabolic disorders in women with PCOS: Beyond the body mass index. J. Endocrinol. Investig. 2018, 41, 383-388. [CrossRef]

50. Cassar, S.; Misso, M.L.; Hopkins, W.G.; Shaw, C.S.; Teede, H.J.; Stepto, N.K. Insulin resistance in polycystic ovary syndrome: A systematic review and meta-analysis of euglycaemic-hyperinsulinaemic clamp studies. Hum. Reprod. 2016, 31, 2619-2631. [CrossRef]

51. Chen, Y.; Zheng, X.; Ma, D.; Zheng, S.; Han, Y.; Su, W.; Liu, W.; Xiao, F.; Lin, M.; Yan, X.; et al. Neck circumference is a good predictor for insulin resistance in women with polycystic ovary syndrome. Fertil. Steril. 2020, 115, 753-760. [CrossRef] [PubMed]

52. Yakar, S.; Rosen, C.J.; Beamer, W.G.; Ackert-Bicknell, C.L.; Wu, Y.; Liu, J.-L.; Ooi, G.T.; Setser, J.; Frystyk, J.; Boisclari, Y.R.; et al. Circulating levels of IGF-1 directly regulate bone growth and density. J. Clin. Investig. 2002, 110, 771-781. [CrossRef]

53. Higashi, Y.; Gautam, S.; Delafontaine, P.; Sukhanov, S. IGF-1 and cardiovascular disease. In Growth Hormone and IGF Research; Churchill Livingstone: London, UK, 2019; Volume 45, pp. 6-16. Available online: https://pubmed.ncbi.nlm.nih.gov/30735831/ (accessed on 31 May 2021).

54. Jeedigunta, Y.; Sultana, S.; Kalashikam, R.R.; Manchala, R. Systemic Inflammation: A Risk Factor for Osteoporosis in Pre-and Post-menopausal Women. J. Women Health Dev. 2020, 3, 423-431. [CrossRef]

55. Greco, E.A. Negative association between trunk fat, insulin resistance and skeleton in obese women. World J. Diabetes 2013, 4, 31 [CrossRef] [PubMed]

56. DeFronzo, R.A.; Gunnarsson, R.; Bjorkman, O.; Olsson, M.; Wahren, J. Effects of insulin on peripheral and splanchnic glucose metabolism in noninsulin-dependent (type II) diabetes mellitus. J. Clin. Investig. 1985, 76, 149-155. [CrossRef]

57. Mario, F.M.; Do Amarante, F.; Toscani, M.K.; Spritzer, P.M. Lean muscle mass in classic or ovulatory PCOS: Association with central obesity and insulin resistance. Exp. Clin. Endocrinol. Diabetes 2012, 120, 511-516. [CrossRef]

58. Comerford, K.B.; Almario, R.U.; Kim, K.; Karakas, S.E. Lean mass and insulin resistance in women with polycystic ovary syndrome. Metabolism 2012, 61, 1256-1260. [CrossRef]

59. Brochu, M.; Mathieu, M.E.; Karelis, A.D.; Doucet, É.; Lavoie, M.E.; Garrel, D.; Rabasa-Lhoret, R. Contribution of the lean body mass to insulin resistance in postmenopausal women with visceral obesity: A monet study. Obesity 2008, 16, 1085-1093. [CrossRef]

60. Gambineri, A.; Patton, L.; Altieri, P.; Pagotto, U.; Pizzi, C.; Manzoli, L.; Pasquali, R. Polycystic ovary syndrome is a risk factor for type 2 diabetes: Results from a long-term prospective study. Diabetes 2012, 61, 2369-2374. [CrossRef] [PubMed]

61. Hill, A.B. The environment and disease: Association or causation? Proc. R. Soc. Med. 1965, 58, 295-300. [CrossRef] [PubMed] 